\title{
Evaluation of the immunocontraceptive potential of Escherichia coli-expressed recombinant dog ZP2 and ZP3 in a homologous animal model
}

\author{
N. Srivastava ${ }^{1}$, R. Santhanam ${ }^{1}$, P. Sheela ${ }^{1}$, S. Mukund ${ }^{1}$, \\ S. S. Thakral' ${ }^{2}$ B. S. Malik ${ }^{2}$ and S. K. Gupta ${ }^{1 *}$ \\ ${ }^{1}$ Gamete Antigen Laboratory, National Institute of Immunology, Aruna Asaf Ali Marg, New \\ Delhi-110067, India; and ${ }^{2}$ Central Military Veterinary Laboratory, Merrut Cantt, UP, India
}

Dog zona pellucida glycoprotein 2 (dZP2), excluding the $\mathrm{N}$-terminal signal sequence and the $\mathrm{C}$-terminal transmembrane-like domain, was cloned and expressed as a polyhistidine fusion protein in Escherichia coli to evaluate the immunocontraceptive efficacy of ZP glycoproteins. The recombinant dZP2 (rec-dZP2) revealed a $70 \mathrm{kDa}$ band corresponding to the full length transcript, as well as several low molecular mass fragments in western blot analysis. In addition to rec-dZP2, E. coli expressed recombinant dog ZP glycoprotein 3 (rec-dZP3), which has also been evaluated for its efficacy to block fertility in a homologous system. Three groups of female dogs $(n=4$ per group) were immunized with rec-dZP2 conjugated to diphtheria toxoid (rec-dZP2-DT), rec-dZP3 conjugated to DT (rec-dZP3-DT) and DT alone. Immunization of female dogs with rec-dZP2-DT and rec-dZP3-DT led to generation of antibodies against the respective ZP proteins as well as to DT. Subsequent to mating, the four female dogs immunized with rec-dZP2-DT all conceived, which is indicative of failure of the anti-rec-dZP2 antibodies to block fertility. In the group of dogs immunized with recdZP3-DT, three of four animals did not conceive when mated with males of proven fertility. The block in fertility was associated with anti-dZP3 antibody titres. Ovarian histopathology revealed that the block in fertility in the group immunized with rec-dZP3-DT is probably manifested by inhibition in the development of follicles and is due to atretic changes in the zona pellucida. These results, although preliminary, indicate that immunization with dZP3 may be a feasible proposition to control dog populations provided that adequate antibody titres are achieved.

\section{Introduction}

The zona pellucida (ZP) glycoproteins play a vital role in mammalian fertilization. In most species, the zona pellucida is composed of at least three biochemically distinct glycoproteins: ZP1, ZP2 and ZP3. In the mouse model, spermatozoa initially bind to ZP3, which triggers the acrosome reaction (Bleil and Wassarman, 1983). Subsequent to the acrosome reaction, ZP2 acts as the secondary receptor and helps in the maintenance of binding of acrosome-reacted spermatozoa to the egg (Bleil et al., 1988). ZP1 has been postulated to cross-link the ZP2-ZP3 heterodimer. ZP2 is proteolytically cleaved after fusion of the sperm membrane with the oolemma and this modification, together with presumed changes in ZP3, is postulated to play an important role in the post-fertilization block to polyspermy (Moller and Wassarman, 1989). This critical role during fertilization has made the ZP glycoproteins potential candidate antigens for immunocontraception.

Antibodies generated against the ZP glycoproteins

*Correspondence

Email: skgupta@nii.res.in purified from a given species show variable degrees of immunological crossreactivity with the ZP glycoproteins from other species (Sacco et al., 1981). The immunological crossreactivity among ZP glycoproteins from different species is a result of a variable degree of amino acid sequence homology and this property has allowed the possibility of heterologous immunization. Initially, pig ZP glycoproteins were used because of the availability of a large number of pig ovaries; the immunological crossreactivity of antibodies generated in this way with zonae pellucidae from various species was demonstrated. Studies in several animal models have demonstrated that the active immunization of female subjects with ZP glycoproteins leads to a block of fertility (Skinner et al., 1984; Dunbar et al., 1989; Sacco et al., 1989; Jones et al., 1992; Paterson et al., 1992; Bagavant et al., 1994).

In several countries, including India, the increasing population of street dogs is a significant problem. It is also associated with a high incidence of rabies. It may be worth exploring the potential of ZP glycoproteins as immunocontraceptive vaccines to control the canine population. Instead of pig ZP glycoproteins, immunization with dog zona proteins per se may generate optimum immune responses with better recognition of native dog zona pellu- 
cida. This effort will demand the availability of large amounts of purified dog zona proteins without contaminants of any other ovarian-associated proteins.

In the present study, the construction of a vector for high expression and single-step purification of recombinant dog ZP2 (rec-dZP2) in Escherichia coli is described. The efficacy of rec-dZP2 conjugated to diphtheria toxoid (DT) as a carrier for regulation of fertility was evaluated in female dogs. In addition, recombinant dog ZP3 (rec-dZP3) expressed in E. coli as described by Santhanam et al. (1998) and conjugated to DT was evaluated for its immunocontraceptive potential. Animals were assessed for antibody response, progesterone concentration, vaginal cytology and conception.

\section{Materials and Methods}

\section{Cloning of $d Z P 2 C D N A$ in a prokaryotic expression vector}

A female dog (aged 1 year) reared at the Animal Facility, National Institute of Immunology, New Delhi, was ovariectomized as per the guidelines and approval of the Institutional Animals Ethics Committee, and her ovaries were snap-frozen in liquid nitrogen. Total RNA was isolated from the frozen ovaries and the poly $(\mathrm{A})^{+}$fraction was purified using the poly A tract mRNA isolation system (Promega, Madison, WI). cDNA was synthesized from the purified poly(A)+ RNA using a Riboclone cDNA synthesis system (Promega). Attempts to directly amplify the full length dZP2 cDNA by PCR failed. Hence, dZP2 was amplified as two fragments by PCR and subsequently assembled as shown (Fig. 1a). The dF1ZP2 fragment (305-1204 bp, excluding the signal sequence) was amplified by PCR using a forward primer with a Sacl restriction site and a reverse primer without a restriction site. The dF2ZP2 fragment (1181-2110 bp, excluding the transmembrane-like domain following the putative furin cleavage site) was amplified by PCR using a forward primer without a restriction site and a reverse primer with a Kpnl restriction site. Primers were designed based on the published sequence of dZP2 (Harris et al., 1994). The dZP2 cDNA was assembled from the purified fragments by a second PCR using Vent DNA polymerase in a $50 \mu \mathrm{l}$ reaction. The cycling conditions for PCR were: (i) one cycle of $94^{\circ} \mathrm{C}$ for $2 \mathrm{~min}, 50^{\circ} \mathrm{C}$ for $2 \mathrm{~min}$ and $72^{\circ} \mathrm{C}$ for $2 \mathrm{~min}$; (ii) addition of $1 \mu \mathrm{mol} \mathrm{I}^{-1}$ of each of the forward (5'-CCGAGCTCACTTCAGTGAACTCAGTA-3' incorporating a Sacl restriction site) and the reverse (5'-CGGGGTACCGGATGATACAGGGCAAGT-3' incorporating a $\mathrm{Kpnl}$ restriction site) primers; (iii) 30 cycles of $94^{\circ} \mathrm{C}$ for $2 \mathrm{~min}, 54^{\circ} \mathrm{C}$ for $2 \mathrm{~min}$ and $72^{\circ} \mathrm{C}$ for $2 \mathrm{~min}$; and (iv) a final extension at $72^{\circ} \mathrm{C}$ for $15 \mathrm{~min}$. The amplified and purified fusion product was initially cloned into the $\mathrm{pCR}$ Script SK(+) cloning vector. The positive pCR Script clone was selected by restriction digestion analysis with Sacl and $K p n l$, and the purified dZP2 fragment was further cloned inframe downstream of the $(\mathrm{His})_{6}$ tag under T5 promoter-lac operator control in the pQE-30 expression vector (QIA (a)
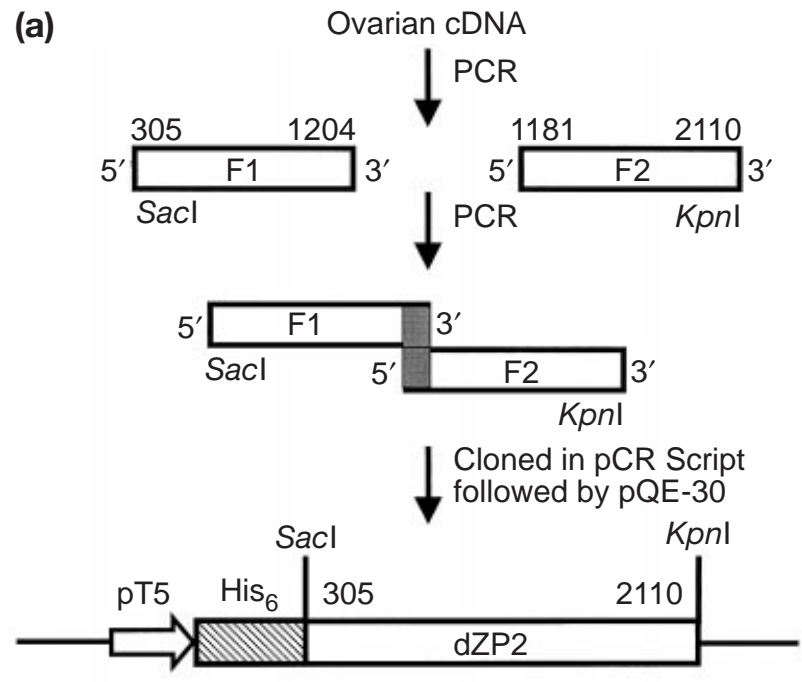

(b)

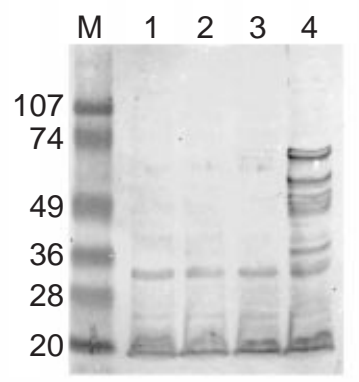

Fig. 1. (a) Schematic representation of the construction of recombinant dog zona pellucida glycoprotein 2 (rec-dZP2) cDNA in PQE-30 expression vector and immunoblot analysis of transformed bacterial cell lysates. The cDNA corresponding to dZP2 (nucleotides 305-2110), excluding the signal sequence and transmembrane-like domain, was assembled by PCR using previous PCR-amplified fragments corresponding to F1 (nucleotides 305-1204) and F2 (nucleotides 1181-2110) as templates. The Sacl-Kpnl-digested 1806 bp dZP2 fragment from the pCR Script SK (+) vector was cloned in-frame downstream of $\mathrm{His}_{6}$ under the phage T5 (pT5) promoter in the pQE-30 vector. Escherichia coli SG13009 [pREP4] transformed with the pQE-dZP2 plasmid was induced with $1 \mathrm{mmol}$ isopropyl- $\beta$-D-thiogalactopyranoside (IPTG) $\mathrm{I}^{-1}$ and processed for immunoblotting. (b) $\mathrm{M}$ : molecular mass marker (kDa); lanes 1 and 2: uninduced and induced wild-type cells; lanes 3 and 4: uninduced and induced SG13009 [pREP4] cells harbouring $\mathrm{pQE}-\mathrm{dZP} 2$ plasmid.

Express; Qiagen GmbH, Hilden). The nucleotide sequence of pQE-dZP2 was confirmed using a forward sequencing primer (5'-GGCGTATCACGAGGCCCTTTCG-3') and a reverse sequencing primer (5'-CATTACTGGATCTATCAACAGG-3') corresponding to $\mathrm{pQE}-30$ vector and the internal primers.

\section{Expression of rec-dZP2 in $\mathrm{E}$. coli}

The SG13009[pREP4] strain of E. coli was transformed with $\mathrm{pQE}-\mathrm{dZP} 2$ plasmid. A positive clone was isolated and 
checked for expression of recombinant protein by western blot analysis. In brief, a single transformed colony was inoculated into $1 \mathrm{ml}$ Luria broth (LB; Difco Laboratories, Detroit, MI) containing $100 \mu \mathrm{g}$ ampicillin $\mathrm{ml}^{-1}$ and $25 \mu \mathrm{g}$ kanamycin $\mathrm{ml}^{-1}$, and was grown overnight at $37^{\circ} \mathrm{C}$. The next day, the cells were subcultured (1:100 dilution) into fresh LB $(1 \mathrm{ml})$ and grown at $37^{\circ} \mathrm{C}$ until the $A_{600}$ reached a value of approximately $0.5-0.6$. The culture was induced with an optimized concentration of $1.0 \mathrm{mmol}$ isopropyl- $\beta$ D-thiogalactopyranoside $\mathrm{I}^{-1}$ (IPTG; Sigma Chemical Co., St Louis, MO) for $2 \mathrm{~h}$. The cells were collected by centrifugation at $1000 \mathrm{~g}$ for $2 \mathrm{~min}$ and the pellet was stored at $-70^{\circ} \mathrm{C}$ until used.

\section{SDS-PAGE and immunoblotting}

The cell pellet obtained from $1 \mathrm{ml}$ culture was solubilized by boiling for $5 \mathrm{~min}$ in $100 \mu \mathrm{l}$ double-strength sample buffer $\left(0.0625\right.$ mol Tris $\mathrm{I}^{-1}, \mathrm{pH} 6.8,2 \%$ (w/v) SDS, $10 \% \quad(\mathrm{v} / \mathrm{v})$ glycerol, $5 \% \quad(\mathrm{v} / \mathrm{v}) \quad \beta$-mercaptoethanol and $0.001 \%(\mathrm{w} / \mathrm{v})$ bromophenol blue). The proteins were resolved by $0.1 \%(\mathrm{w} / \mathrm{v})$ SDS-10\% $(\mathrm{w} / \mathrm{v})$ polyacrylamide gel electrophoresis (Laemmeli, 1970). For immunoblotting, the proteins were transferred by electrophoresis to $0.45 \mu \mathrm{m}$ nitrocellulose membrane (BioRad, Hercules, CA) overnight at a constant voltage of $15 \mathrm{~V}$ in Tris glycine buffer with $20 \%$ (v/v) methanol (Towbin et al., 1979). Blots were developed with 1:1000 dilution of polyclonal antibodies generated in rabbits against the pig solubilized zona pellucida (pSIZP) as described by Kaul et al. (1997).

\section{Purification of rec-dZP2 and rec-dZP3}

For purification of rec-dZP2 fusion protein from the inclusion bodies, SG13009[pREP4] cells transformed with the pQE-dZP2 plasmid were grown $\left(A_{600}=0.7\right)$ at shake flask level $(250 \mathrm{ml}$ culture flask, total volume $2 \mathrm{l}$ ) and induced with $1 \mathrm{mmol}$ IPTG $\mathrm{I}^{-1}$ for $2 \mathrm{~h}$. The cells were harvested by centrifugation at $1500 \mathrm{~g}$ for $30 \mathrm{~min}$ at $4^{\circ} \mathrm{C}$ and the pellet was stored at $-70^{\circ} \mathrm{C}$ until required. The cell pellet was sonicated in sonication buffer $(50 \mathrm{mmol}$ phosphate buffer I-1, 300 mmol $\mathrm{NaCl} \mathrm{I}^{-1}, \mathrm{pH}$ 7.8) and inclusion bodies were solubilized in buffer A ( 6 mol guanidine hydrochloride $\mathrm{I}^{-1}, 100 \mathrm{mmol} \mathrm{NaH}_{2} \mathrm{PO}_{4} \mathrm{I}^{-1}, 10 \mathrm{mmol}^{\text {Tris I }}{ }^{-1}, \mathrm{pH} 8.0 ; 5 \mathrm{ml}$ buffer $\mathrm{A} / \mathrm{g}$ inclusion bodies). The total cell lysate was centrifuged at $10000 \mathrm{~g}$ for $5 \mathrm{~min}$ at $4^{\circ} \mathrm{C}$ and the supernatant containing the recombinant fusion protein was purified using nickel-nitrilotriacetic acid (Ni-NTA) resin (Qiagen $\mathrm{GmbH}$ ) as described by Kaul et al. (1997). The eluted fractions, showing the presence of rec-dZP2 in western blot analysis, were concentrated in an Amicon concentrator using a YM30 membrane (Amicon, Lexington, MA) and dialysed against $100 \mathrm{mmol}$ phosphate buffer $\mathrm{I}^{-1}, \mathrm{pH} 7.4$, containing 4 mol urea $\mathrm{I}^{-1}$. The purified recombinant protein was quantified by bicinchoninic acid (Sigma Chemical Co.).

The cDNA corresponding to dZP3, excluding the $\mathrm{N}$ terminal signal sequence and the C-terminus transmembranelike domain, was cloned in pQE-30 vector and the recombinant protein was expressed as $\mathrm{His}_{6}$-fusion protein in $E$. coli as described by Santhanam et al. (1998). The recdZP3 was purified essentially as described for rec-dZP2 and analysed by western blot analysis using murine monoclonal antibody (MA-451) generated against pig ZP3 $\beta$ (a homologue of dZP3) and immunologically crossreactive with dog zona pellucida as described by Santhanam et al. (1998).

\section{Conjugation of rec-dZP2 and rec-dZP3 to DT}

Rec-dZP2 (10 mg) was conjugated to $8.0 \mathrm{mg}$ DT using the 'one-step' glutaraldehyde coupling procedure at a molar ratio of $1: 1$. In brief, conjugation was performed in $100 \mathrm{mmol}$ phosphate buffer $\mathrm{I}^{-1}, \mathrm{pH} 7.4$ with 4 mol urea $\mathrm{I}^{-1}$ using $0.1 \%$ $(\mathrm{v} / \mathrm{v})$ glutaraldehyde, overnight at $4^{\circ} \mathrm{C}$ with gentle end-to-end mixing. Unreacted sites were blocked by incubation with $100 \mathrm{mmol}^{2}$ lysine $\mathrm{I}^{-1}$ for $3 \mathrm{~h}$ at room temperature. The conjugate was dialysed against PBS $(10 \mathrm{mmol}$ phosphate buffer $\left.{ }^{-1}, 150 \mathrm{mmol} \mathrm{NaCl} \mathrm{I}^{-1}, \mathrm{pH} 7.4\right)$ containing $0.3 \mathrm{~mol}$ urea $\mathrm{I}^{-1}$. The same coupling procedure was used to conjugate $10.0 \mathrm{mg}$ rec-dZP3 to $6.0 \mathrm{mg}$ DT (molar ratio $2: 1$ ).

\section{Immunization of rabbits with rec-dZP2-DT and reactivity of the immune sera with dog zona pellucida}

Two female New Zealand white rabbits (Small Experimental Animal Facility, National Institute of Immunology, New Delhi) were immunized intradermally at multiple sites with $250 \mu \mathrm{g}$ rec-dZP2-DT emulsified in complete Freund's adjuvant (CFA). The animals were given two i.m. booster injections at 4 week intervals with an equivalent amount of rec-dZP2-DT in incomplete Freund's adjuvant (IFA). Blood was collected from the immunized animals through the ear vein before initiation of immunization and at 2 weeks after the second booster. The reactivity of the pre-immune and immune serum samples with dog zona pellucida was assessed by an indirect immunofluorescence assay on dog ovarian cryo-sections essentially as described by Santhanam et al. (1998).

\section{Immunization of female dogs}

The female dogs ( $n=12$; aged 3-5 years) used in the present study were reared at the Central Military Veterinary Laboratory (Meerut Cantt, Meerut, India). Active immunization studies were initiated according to the guidelines and with the approval of the Institutional Animals Ethics Committee. The animals were divided randomly into three groups ( $n=4$ dogs per group). The animals were immunized i.m. at two sites with rec-dZP2-DT (dogs 6, 7, 11 and 12 ; equivalent to $250 \mu \mathrm{g}$ rec-dZP2 per animal), recdZP3-DT (dogs 1, 3, 4 and 5; equivalent to $250 \mu \mathrm{g}$ recdZP3 per animal) or DT (dogs 2, 8, 9 and 10; equivalent to $250 \mu \mathrm{g}$ DT per animal), emulsified in Squalene (Sigma Chemical Co.) and Arlacel-A (Sigma Chemical Co.) in a $4: 1$ ratio. Sodium phthalyl derivative of lipopolysaccharide (1 mg; SPLPS), prepared as described by Elin et al. (1981), was also included in the first injection as an additional 
adjuvant. Primary immunization of dogs comprised three injections of the respective proteins at monthly intervals. Blood samples (2-3 ml) were collected before and at day 15 after each injection from the ante-cubital vein for determination of progesterone concentrations and antibody titres. The dogs were subsequently given booster injections with the respective immunogens (equivalent amount to first injection) to maintain the desired antibody titre until the dogs entered oestrus. The immunized female dogs were kept for 3 days with males of proven fertility for mating at day 5 after pro-oestrous bleeding. Bleeding at the time of pro-oestrus was associated with vaginal swelling and the ability of female dogs to attract the male dogs. In addition, vaginal smears were taken and examined for the presence of cornified epithelial cells. Rates of conception, serum progesterone concentrations and antibody titres were recorded for the female dogs.

\section{ELISA}

The microtitre plates were coated with optimized concentrations of rec-dZP2 (250 ng per well), rec-dZP3 (250 ng

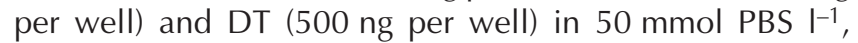
$\mathrm{pH} 7.4$ at $37^{\circ} \mathrm{C}$ for $1 \mathrm{~h}$ and incubated overnight at $4^{\circ} \mathrm{C}$. The plates were blocked with $1 \%(\mathrm{w} / \mathrm{v})$ BSA in PBS and processed for determination of antibody titres as described by Santhanam et al. (1998). For each serum sample tested, a reciprocal of the serum dilution giving an absorbance of 1.0 was calculated by regression analysis and is represented as antibody units (AU). One serum sample from each assay was used in the next assay as an internal control. The interassay coefficient of variation was $<10 \%$.

\section{Radioimmunoassay for progesterone}

Serum progesterone concentration was determined by radioimmunoassay using the WHO matched assay reagent programme as described by Sufi et al. (1999).

\section{Ovarian histology}

Animals immunized with rec-dZP2-DT (dogs 7 and 12), rec-dZP3-DT (dogs 1, 3 and 5) or DT (dogs 2, 8 and 9) were administered with xylazine and ketamine hydrochloride (2 $\mathrm{mg} \mathrm{kg}^{-1}$ body weight) i.v. on day 380 after the initiation of immunization, as general anaesthesia. The ovaries were surgically removed, fixed in buffered $10 \%(\mathrm{v} / \mathrm{v})$ formalin for $48 \mathrm{~h}$ and processed for paraffin wax sections. The sections were stained with haematoxylin and eosin using standard protocols. For each ovary, six to eight non-adjacent sections were chosen randomly and examined under a light microscope for ovarian pathology with respect to follicular development, cystic changes or infiltration by lymphocytes.

\section{Results}

\section{Expression and purification of rec-dZP2 and rec-dZP3}

The dZP2 cDNA (305-2110 bp) encoding a polypeptide of 602 amino acids, excluding the signal sequence and

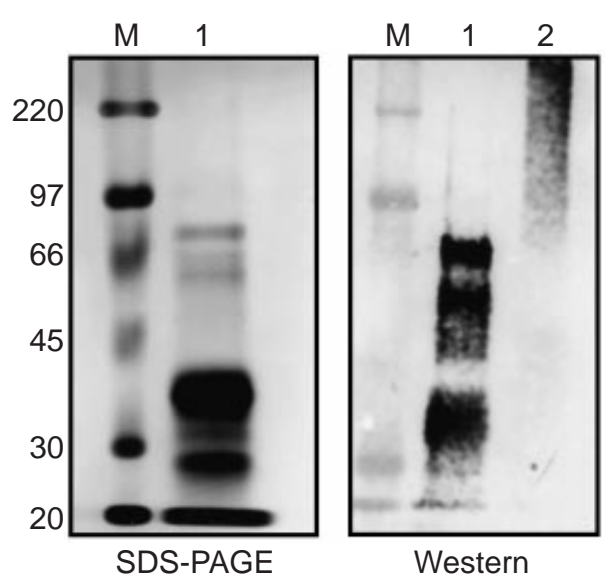

Fig. 2. Electrophoretic analysis (SDS-PAGE) and western blot analysis of purified recombinant dog zona pellucida glycoprotein 2 (rec-dZP2) and its conjugate with diphtheria toxoid (rec-dZP2-DT). The Escherichia coli-expressed rec-dZP2 was purified on a nickelnitrilotriacetic acid agarose affinity column. The purified recombinant protein was conjugated to DT using $0.1 \%(\mathrm{v} / \mathrm{v})$ glutaraldehyde as coupling agent. Left panel: $M$ : molecular mass markers $(\mathrm{kDa})$; lane 1: purified rec-dZP2. Right panel: M: molecular mass markers (kDa); lane 1: purified rec-dZP2; lane 2: rec-dZP2-DT.

transmembrane-like domain, was assembled by PCR and cloned in-frame under the control of T5 promoter and lac operator control in the pQE-30 expression vector. The nucleotide sequence of dZP2 revealed three changes ( $C$ to $G$, G to $C$ and $C$ to $T$ at positions 1079, 1080 and 1087, respectively) compared with the previously published dZP2 sequence (Harris et al., 1994). These changes in the sequence led to one change in the amino acid sequence (arginine to alanine at position 292). The numbering of the nucleotides and amino acids is as for the dZP2 precursor protein.

SG13009[pREP4] cells were transformed with the recombinant plasmid. The typical immunoblot result of one of the transformed clones is shown (Fig. 1b). The rec-dZP2 protein had an apparent molecular mass of $70 \mathrm{kDa}$. In addition, several low molecular mass fragments were also observed. Optimum expression of rec-dZP2 was observed when the cells were grown for $2 \mathrm{~h}$ with $1 \mathrm{mmol}$ IPTG $\mathrm{I}^{-1}$ (data not shown). The expression of rec-dZP2 was tightly regulated, as expression was not observed in the noninduced transformed cells. Cellular localization studies revealed that the rec-dZP2 was present in the inclusion bodies and was not secreted in the periplasm (data not shown). The SDS-PAGE profile of $\mathrm{Ni-NTA-purified} \mathrm{rec-}$ dZP2 revealed that, in addition to the $70 \mathrm{kDa}$ band corresponding to the full length transcript, three major bands of 60, 35 and $25 \mathrm{kDa}$ and two minor bands of 65 and $31 \mathrm{kDa}$ were also observed (Fig. 2, left panel, lane 1). The $25 \mathrm{kDa}$ band, as observed in SDS-PAGE, did not react in western blot analysis (Fig. 2, right panel, lane 1). With the shakeflask method, approximately $7.0 \mathrm{mg}$ rec-dZP2 was obtained from 1 I of culture. 


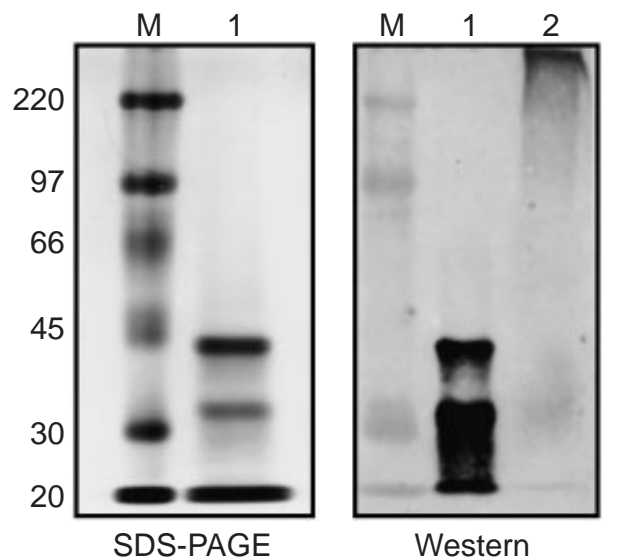

Fig. 3. Electrophoretic analysis (SDS-PAGE) and western blot analysis of purified recombinant dog zona pellucida glycoprotein 3 (rec-dZP3) and its conjugate with diphtheria toxoid (rec-dZP3-DT). The rec-dZP3 was purified on a nickel-nitrilotriacetic acid agarose affinity column. Left panel: M: molecular mass markers (kDa); lane 1: purified rec-dZP3 Right panel: M: molecular mass markers; lane 1: purified rec-dZP3; lane 2: rec-dZP3-DT.

Expression of rec-dZP3 in E. coli strain SG13009[pREP4] was reported by Santhanam et al. (1998). The rec-dZP3 His 6 fusion protein was also purified by Ni-NTA resin. The purified rec-dZP3 in SDS-PAGE (Fig. 3, left panel, lane 1), as well as western blot analysis (Fig. 3, right panel, lane 1), revealed a $42 \mathrm{kDa}$ band corresponding to the full length transcript. In addition, a $32 \mathrm{kDa}$ band was observed. Conjugation of purified rec-dZP2 and rec-dZP3 with DT was confirmed by a shift in the mobility of the respective bands in western blot analysis (Fig. 2, right panel, lane 2; Fig. 3, right panel, lane 2).

Recognition of native dog zona pellucida by polyclonal rabbit antibodies against rec-dZP2-DT or rec-dZP3-DT

Rabbits immunized with rec-dZP2-DT had high antibody titres against rec-dZP2 (R-190, 26300 AU; and R-191, $32400 \mathrm{AU}$ ) as observed in ELISA. Before assessing the immunocontraceptive potential of the rec-dZP2 in dogs, the ability of the rabbit polyclonal antibodies against recdZP2-DT to recognize dog zona pellucida was evaluated by an indirect immunofluorescence assay (Fig. 4). Anti-recdZP2 antibodies showed positive fluorescence with dog zona pellucida and did not recognize other ovarian cells. No fluorescence was observed when pre-immune serum from the same immunized animal was used. Rabbit polyclonal anti-rec-dZP3 antibodies also recognized the native dog zona pellucida as described by Santhanam et al. (1998).

Immunization of female dogs with rec-dZP2-DT, recdZP3-DT or DT, and their effect on fertility

Immunization with rec-dZP2-DT. Immunization of four female dogs (dogs $6,7,11$ and 12) with rec-dZP2-DT
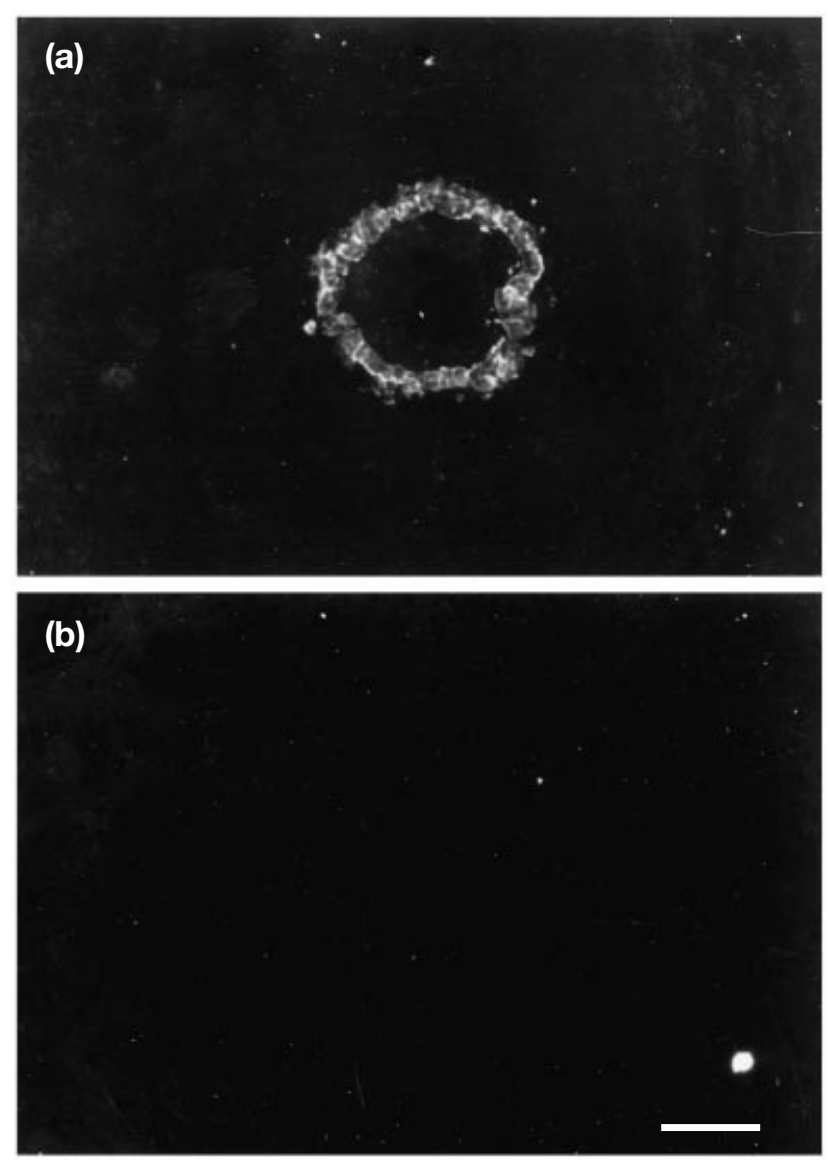

Fig. 4. Reactivity of rabbit anti-rec-dZP2 (anti-recombinant dog zona pellucida glycoprotein 2 ) serum with native dog zona pellucida by indirect immunofluorescence. Dog ovarian cryosections $(5 \mu \mathrm{m}$ thickness) were incubated with 1:200 dilution of rabbit antirec-dZP2-DT (anti-rec-dZP2 conjugated with diphtheria toxoid) (a) immune or (b) preimmune serum followed by incubation with 1:2000 dilution of fluorescein isothiocyanate (FITC)-labelled anti-rabbit immunoglobulins. Representative immunofluorescence patterns are shown. Scale bar represents $120 \mu \mathrm{m}$.

conjugate induced an antibody response against rec-dZP2 in all the immunized animals, range 0.4-99.2 $\times 10^{3} \mathrm{AU}$ (Fig. 5). Dog 6 had higher anti-rec-dZP2 antibody titres than $\operatorname{dogs} 7,11$ and 12. All the immunized animals also showed high antibody titres against DT. The antibody titres against DT were at least 10-40-fold higher than titres against recdZP2 (Fig. 5, Table 1). Animals were given boosters to maintain the antibody titres until the dogs entered oestrus. An increase in the antibody titre was observed in all the animals after the booster injections. Immunization of female dogs with rec-dZP2-DT did not lead to a block of oestrus. During oestrus, the immunized females attracted the males for mating. Oestrus was confirmed by an increase in serum progesterone concentrations as well as by vaginal cytology (for example, presence of cornified epithelial cells). All four of the dogs immunized with rec-dZP2-DT became pregnant, thereby indicating that the antibodies against recdZP2 failed to block fertility (Fig. 5, Table 1). 


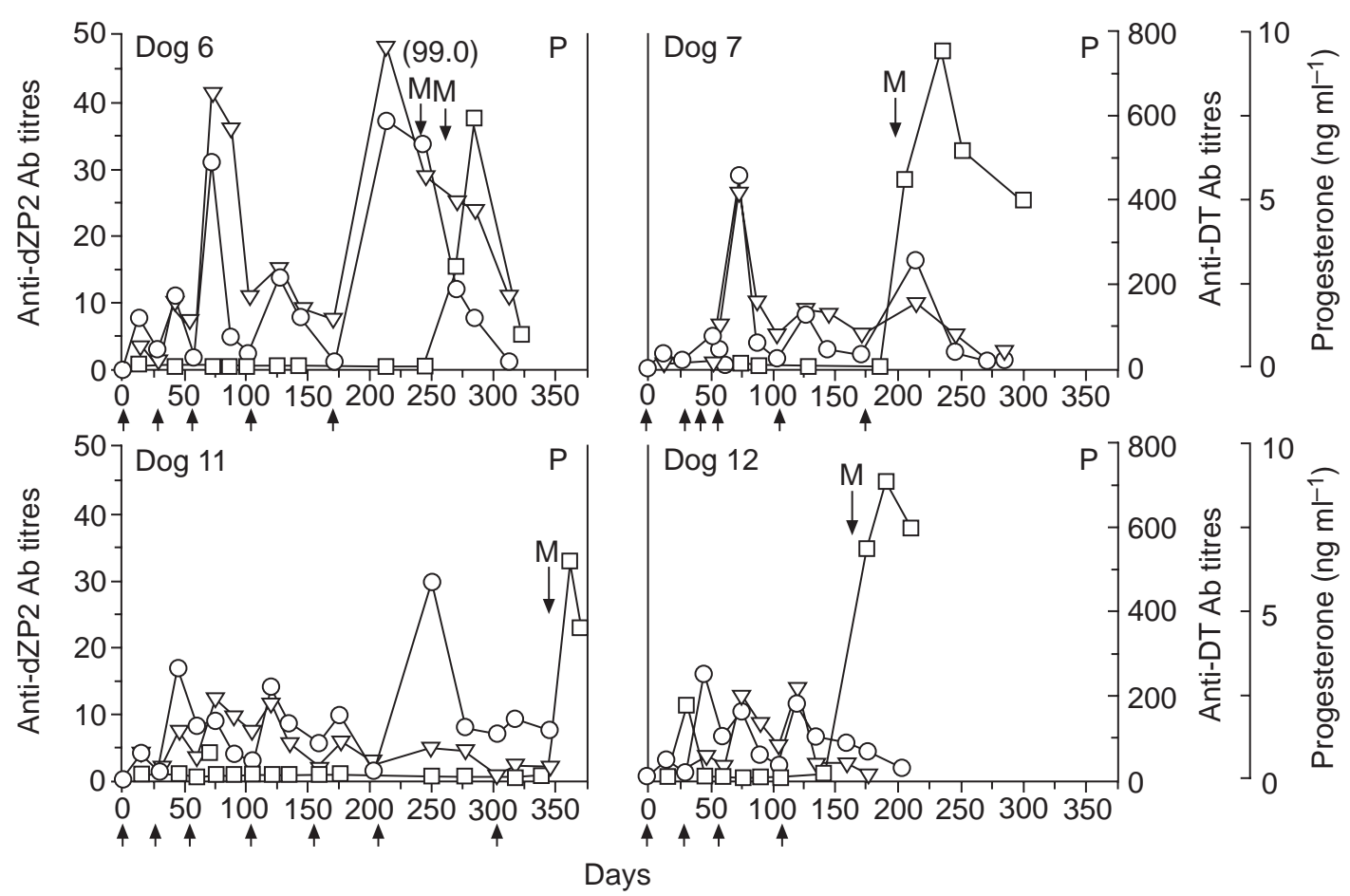

Fig. 5. Antibody titres, progesterone profile and status of fertility in four female dogs immunized with recombinant dog zona pellucida glycoprotein 2 conjugated to diphtheria toxoid (rec-dZP2-DT). The immunization schedule is indicated by arrows along the $x$ axis. The anti-rec-dZP2 $(\nabla)$ and anti-DT $(O)$ antibody $(A b)$ titres are expressed as antibody units $(\mathrm{AU}) \times 10^{-3}$. $\square$ : Progesterone; M: time of mating; P: pregnancy.

Table 1. Effect of immunization with rec-dZP2-DT, rec-dZP3-DT and DT on fertility in female dogs

\begin{tabular}{|c|c|c|c|c|c|}
\hline \multirow{2}{*}{$\begin{array}{l}\text { Experimental } \\
\text { group }\end{array}$} & \multicolumn{2}{|c|}{ Antibody titre range $\left(\mathrm{AU} \times 10^{3}\right)$ against } & \multirow{2}{*}{$\begin{array}{l}\text { Number of } \\
\text { matings }\end{array}$} & \multirow{2}{*}{$\begin{array}{l}\text { Anti-dZP2 or anti-dZP3 } \\
\text { titre at time of mating } \\
\qquad\left(A \cup \times 10^{3}\right)\end{array}$} & \multirow{2}{*}{$\begin{array}{c}\text { Pregnancy } \\
\text { (number of pups) }\end{array}$} \\
\hline & dZP2 or dZP3 & DT & & & \\
\hline \multicolumn{6}{|c|}{ Immunization with rec-dZP2-DT } \\
\hline Dog 6 & $1.1-99.2$ & $13.7-595.0$ & 2 & $\sim 99.0$ & Pregnant (4) \\
\hline $\operatorname{Dog} 7$ & $0.6-26.1$ & $20.0-461.0$ & 1 & $\sim 5.0$ & Pregnant (6) \\
\hline Dog 11 & $0.7-12.2$ & $20.0-474.0$ & 1 & $\sim 2.0$ & Pregnant (4) \\
\hline Dog 12 & $0.4-13.4$ & $12.0-180.0$ & 1 & $\sim 2.1$ & Pregnant (3) \\
\hline \multicolumn{6}{|c|}{ Immunization with rec-dZP3-DT } \\
\hline Dog 1 & $0.7-26.0$ & $10.0-461.0$ & 1 & $\sim 6.0$ & No pregnancy \\
\hline $\operatorname{Dog} 3$ & $0.7-18.8$ & $10.0-1760.0$ & 1 & $\sim 0.7$ & Pregnant (5) \\
\hline $\operatorname{Dog} 4$ & $0.8-12.8$ & $20.4-608.0$ & 3 & $\sim 2.0$ & No pregnancy \\
\hline $\operatorname{Dog} 5$ & $0.7-93.1$ & $11.4-1083.0$ & 1 & $\sim 8.8$ & No pregnancy \\
\hline \multicolumn{6}{|c|}{ Immunization with DT } \\
\hline Dog 2 & nd & $4.8-267.0$ & 2 & nd & Pregnant (4) \\
\hline $\operatorname{Dog} 8$ & nd & $4.6-153.0$ & 1 & nd & No pregnancy \\
\hline Dog 9 & nd & 10.9-291.0 & 1 & nd & Pregnant (5) \\
\hline Dog 10 & nd & $12.8-365.0$ & 1 & nd & Pregnant (3) \\
\hline
\end{tabular}

rec-dZP2-DT: recombinant dog zona pellucida glycoprotein 2 conjugated to diphtheria toxoid; rec-dZP3-DT: recombinant dog zona pellucida glycoprotein 3 conjugated to diphtheria toxoid; AU: antibody units; nd: not detected.

Immunization with rec-dZP3-DT. Immunization of four female dogs (dogs 1, 3, 4 and 5) with rec-dZP3-DT conjugate induced an antibody response against rec-dZP3 in the immunized animals, range 0.7-93.1 × 10 $3 \mathrm{AU}$ (Fig. 6,
Table 1). Dogs 1 and 5 had a higher anti-rec-dZP3 antibody response than dogs 3 and 4 . The anti-DT antibody response ranged from 10 to $1760 \times 10^{3} \mathrm{AU}$. All the dogs in the recdZP3-DT immunized group showed normal oestrus. Three 

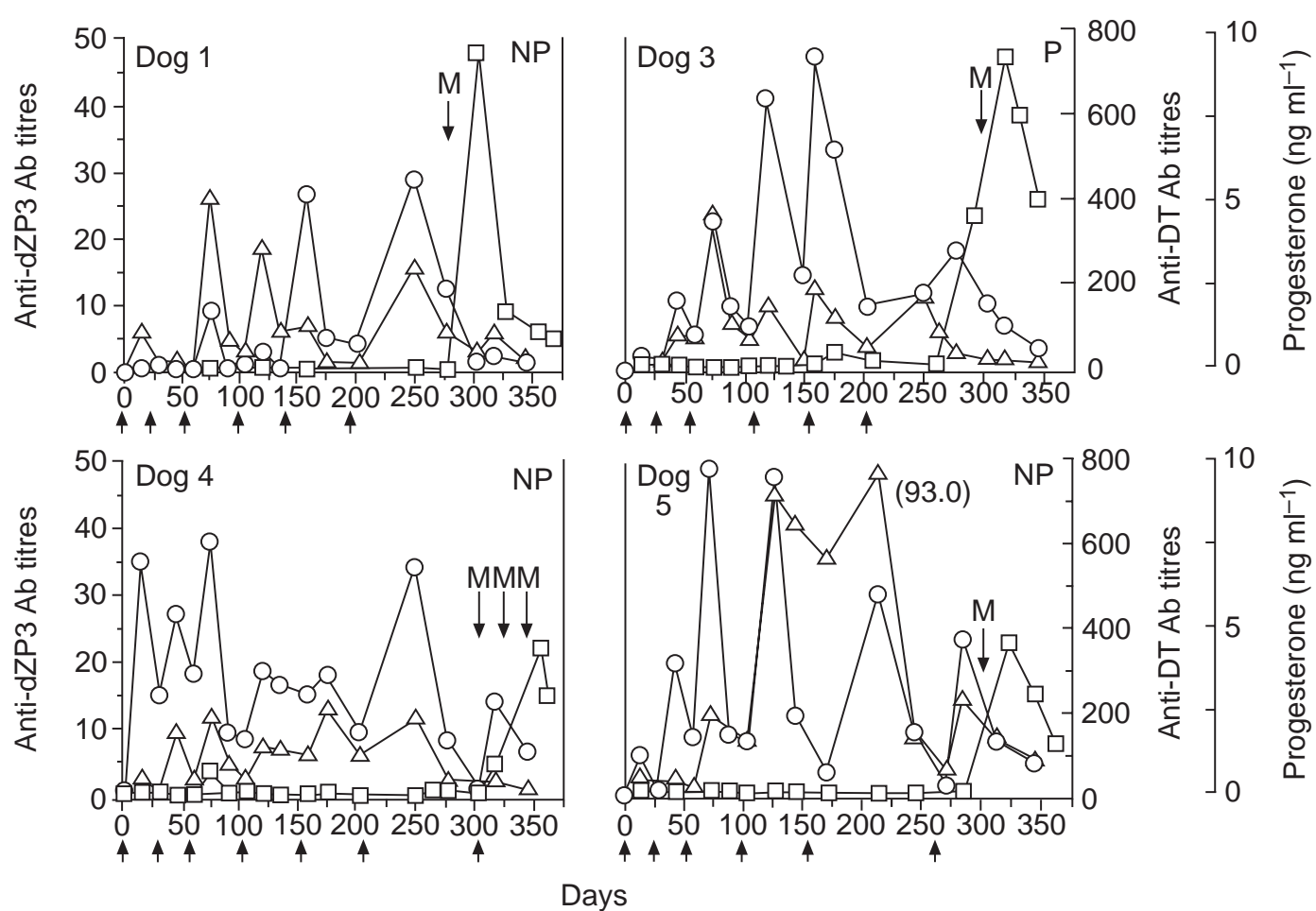

Fig. 6. Antibody titres, progesterone profile and status of fertility in four female dogs immunized with recombinant dog zona pellucida glycoprotein 3 conjugated to diphtheria toxoid (rec-dZP3-DT). The immunization schedule is indicated by arrows along the $x$ axis. The anti-rec-dZP3 $(\triangle)$ and anti-DT $(\bigcirc)$ antibody $(A b)$ titres are expressed as antibody $(\mathrm{Ab})$ units $(\mathrm{AU}) \times 10^{-3}$. $\square$ : Progesterone; $\mathrm{M}$ : time of mating; P: pregnancy; NP: not pregnant.

of four immunized females (dogs 1, 4 and 5) did not conceive when mated during oestrus. Dog 3 became pregnant subsequent to mating. The anti-dZP3 antibody titre in dog 3 was lower than that of the immunized animals that failed to conceive (Fig. 6). At the time of mating, dog 3 had an antirec-dZP3 antibody titre of $0.7 \times 10^{3} \mathrm{AU}$.

Immunization with DT. The four animals (dogs 2, 8, 9 and 10) immunized with DT showed anti-DT antibody titres ranging from 4.6 to $365.0 \times 10^{3} \mathrm{AU}$ (Fig. 7, Table 1). In the DT-immunized group, three of four animals became pregnant subsequent to mating (Fig. 7, Table 1). The fourth animal (dog 8) did not conceive, probably due to the low concentration of serum progesterone at the time of oestrus.

\section{Ovarian morphology of the female dogs immunized with $D T$, rec-dZP2-DT and rec-dZP3-DT}

Histopathology of the ovaries from the DT-immunized group revealed follicles at the various stages of development without any degenerated follicles (Fig. 8a,b). The zona pellucida appeared normal. The ovarian histology of the dogs immunized with rec-dZP2-DT also showed normal patterns of follicle development (Fig. 8c,d). However, in the dogs immunized with rec-dZP3-DT, inhibition of follicular development and degenerative changes in the zona pellu- cida were observed (Fig. 8e,f). No infiltration by lymphocytes was observed in atretic follicles. These changes were associated with the antibody titres, as dogs 1 and 5 showed a more pronounced increase in the number of atretic follicles compared with dog 3 (data not shown).

\section{Discussion}

ZP glycoproteins will be required in large quantities, preferably free from other ovarian-associated proteins, for evaluation of their immunocontraceptive potential. Moreover, large-scale production of the antigen has to be economically viable to produce a vaccine for practical use. Attempts have been made by several groups to express ZP2, the secondary sperm receptor, from various species such as rabbits (Lee et al., 1993; Vandevoort et al., 1995), pigs (Tsubamoto et al., 1999) and bonnet monkeys (Jethanandani et al., 1998) using various types of expression systems to overcome these problems. It is thought that the processing of ZP glycoproteins within maturing oocytes for incorporation within the zona matrix involves the removal of the signal peptide by signal peptidase and the transmembrane-like domain at the upstream furin cleavage site by furin proteases (von Heijne, 1986; Hosaka et al., 1991). Hence, rec-dZP2, excluding the $\mathrm{N}$-terminal signal sequence and C-terminal transmembrane-like domain, was 


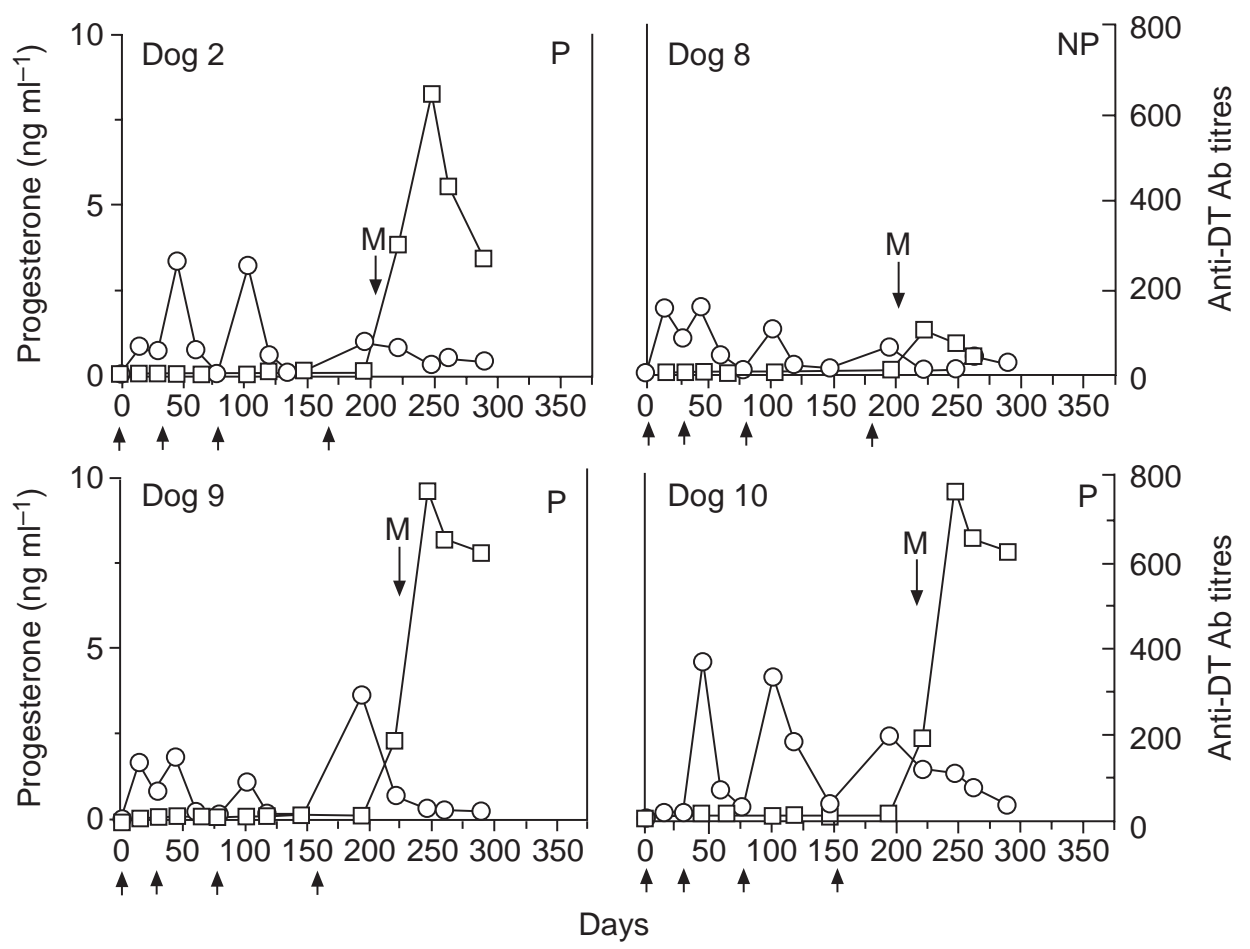

Fig. 7. Antibody titres, progesterone profile and status of fertility in female dogs immunized with diphtheria toxoid (DT). The immunization schedule is indicated by arrows along the $x$ axis. The anti-DT antibody (Ab) titres (O) are expressed as antibody units (AU) $\times 10^{-3}$. $\square$ : Progesterone; M: time of mating; P: pregnancy; NP: not pregnant.

expressed in E. coli as $\mathrm{His}_{6}$ fusion protein, which allowed it to be purified easily. The presence of lower molecular mass fragments in addition to the protein $(70 \mathrm{kDa})$ corresponding to the full length transcript may be due to either degradation of the expressed protein or premature termination during the translation of the dZP2 mRNA.

The availability of rec-dZP2 expressed in E. coli, which is devoid of other ovarian proteins as contaminants, prompted us to evaluate its efficacy to block fertility using a homologous animal model. In addition, rec-dZP3 expressed in E. coli, as reported by Santhanam et al. (1998), was included for evaluation of its efficacy to block fertility. The rec-dZP2 and rec-dZP3 will be recognized essentially as self-antigens in female dogs. Rec-dZP2 and rec-dZP3 were conjugated to DT as a carrier protein to make them immunogenic. Previous clinical trials of the contraceptive vaccine in women, consisting of a heterospecies dimer of the $\beta$-subunit of hCG associated non-covalently with the $\alpha$-subunit of ovine $\mathrm{LH}$, have demonstrated that tetanus toxoid (TT) and DT are excellent carrier proteins (Talwar et al., 1994). Rec-dZP2 and rec-dZP3 were conjugated with DT using glutaraldehyde, a commonly used coupling agent. Several heterobifunctional reagents such as 1-ethyl3-(3 diethylaminopropyl)-carbodiimide (EDCI) and M-maleimidobenzoyl-N-hydroxysuccinamide ester (MBS) have also been used to prepare conjugates with defined stoichiometry. Previous studies from our laboratory have demonstrated that conjugation of either recombinant zona proteins or their corresponding synthetic peptides with DT, using glutaraldehyde as a coupling agent, generates effective antibody responses leading to a block in fertility (Govind and Gupta, 2000; Kaul et al., 2001). Hence, glutaraldehyde was preferred as a coupling agent. It is a simple and effective method of coupling, although has a risk of formation of homopolymers and heterogeneous populations of the resulting conjugate. The conjugation of recdZP2 and rec-dZP3 with DT was confirmed by western blot analysis.

Antisera raised in rabbits against rec-dZP2-DT recognized the dog native ZP and did not react with any other type of cell in the ovary. Evaluation of the immunoreactivity of the antibodies generated in female dogs against recdZP2-DT and rec-dZP3-DT with dog zona pellucida could not be performed with certainty because of the high immunofluorescence background on sections of dog ovary with dog pre-immune serum samples.

Immunization of the female dogs with the rec-dZP2-DT emulsified with Squalene and Arlacel-A (SPLPS as an additional adjuvant only in the first injection) generated an adequate antibody response against rec-dZP2 as well as DT in all the animals immunized. However, 10- to 40-fold higher anti-DT antibody titres compared with antibody titres against rec-dZP2 could be a result of the fact that dZP2 might have been recognized essentially as a self-antigen. 

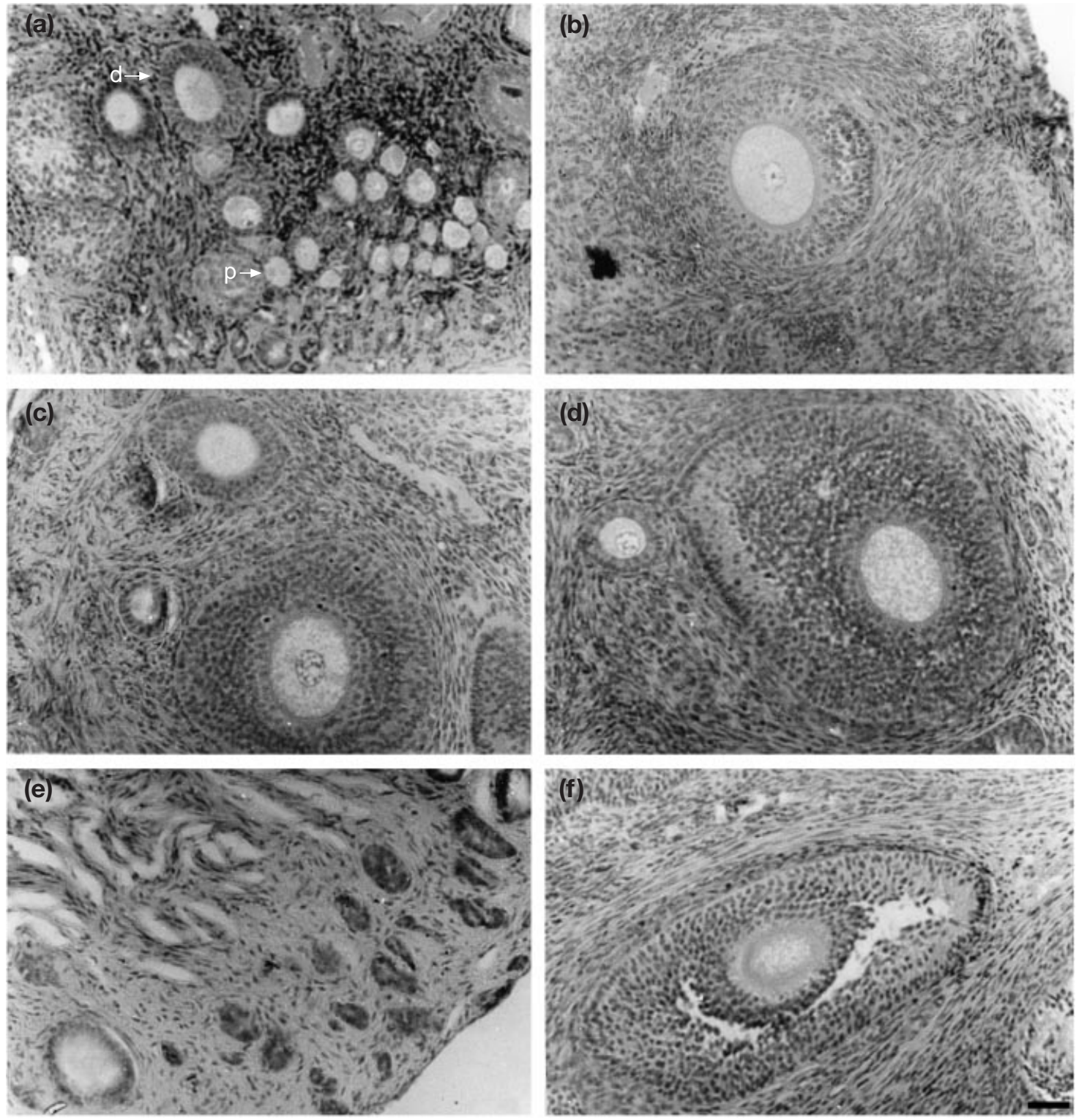

Fig. 8. Photomicrographs of ovarian sections of female dogs immunized with diphtheria toxoid (DT), recombinant dog zona pellucida glycoprotein 2 conjugated to DT (rec-dZP2-DT) and rec-dZP3-DT. The sections were stained with haematoxylin and eosin. (a,b) Ovarian morphology from dogs immunized with DT (a: dog 2; b: dog 8) showing normal folliculogenesis with primordial (p) and developing (d) follicles. (c,d) Ovarian sections from dogs immunized with rec-dZP2-DT (c: dog 7; d: dog 12) showing follicles in different stages of development. (e,f) Ovarian sections from dogs immunized with rec-dZP3-DT (e: $\operatorname{dog} 1$; f: dog 5) showing atretic follicles. Scale bar represents $100 \mu \mathrm{m}$.

Despite the presence of anti-rec-dZP2 antibodies, all the immunized females conceived when mated with a male during oestrus. The mean number of pups born to dogs immunized with rec-dZP2-DT was not significantly different (Student's $t$ test) from the number born to the dogs immunized with DT. The ovarian histology of the dogs immunized with rec-dZP2-DT revealed normal follicular development. Immunization of cynomolgus monkeys with bacterially expressed $75 \mathrm{kDa}$ rabbit ZP protein (homologue of dZP2) conjugated to protein A generated antibodies that interfered with follicular development and ovarian cyclicity
(Vandevoort et al., 1995); however, the status of fertility was not evaluated by these workers. Failure to block fertility and apparent normal ovarian morphology in female dogs immunized with rec-dZP2-DT may be a result of either low antibody titres or qualitative differences in the antibodies generated.

Active immunization of bitches with crude pig zona pellucida together with CFA induced infertility (MahiBrown et al., 1982). Immunization resulted in abnormal oestrous cycles characterized by prolonged pro-oestrus and oestrus. Oocytes recovered from the ovaries of the 
immunized animals failed to bind spermatozoa. Histological examination of the ovaries revealed that the animals with the highest antibody titres showed depletion of oocytes (Mahi-Brown et al., 1988). Subsequently, these investigators immunized bitches with pig zona pellucida adsorbed on alum together with CP20, 961, a synthetic lipid amine, as an emulsifier, resulting in a variable antibody response (Mahi-Brown et al., 1985). One of the animals developed a temporary inflammatory response to the adjuvant at the site of injection, had the lowest antibody response and conceived after mating, whereas the other animals had higher antibody titres, remained infertile and did not show any inflammatory response. However, these studies used solubilized zona pellucida and the contraceptive efficacy could not be related to a particular zona glycoprotein. The potential of purified pig ZP glycoproteins to control canine populations was further demonstrated by Fayrer-Hosken et al. (2000).

In the present study, three of four female dogs immunized with rec-dZP3-DT did not conceive after mating during oestrus. Low anti-rec-dZP3 antibody titres (approximately $0.7 \times 10^{3} \mathrm{AU}$ ) in the fourth dog at the time of mating may not have been adequate to prevent conception. It is difficult to assess the protective threshold level of anti-recdZP3 antibody titres from this study, but failure to conceive, when the antibody titres were approximately $2.0 \times 10^{3} \mathrm{AU}$ indicates that antibody titres $\geqslant 2.0 \times 10^{3} \mathrm{AU}$ will be required to achieve the contraceptive effect. Between six and seven injections of rec-dZP3-DT, over a period of > 350 days, were administered to study its contraceptive efficacy. It is desirable that the number of injections required to achieve contraception should be reduced to make it a practical proposition. Further optimization to enhance the antibody response against rec-dZP3 could be achieved by incorporating more potent adjuvants. In addition to conventional immunization, various other strategies such as viral vector or liposomes could also be used. Immunization of mice with recombinant ectomelia virus (a natural pathogen for mice) expressing mouse ZP3 led to a decrease in fertility as well as litter size (Jackson et al., 1998). A single injection of pig solubilized zona pellucida using a liposome delivery system decreased pup production by grey seals (Halihoerus grypus) by $90 \%$ over a period of 5 years (Brown et al., 1997). Single injection of TT entrapped in polylactide-co-glycolide and polylactide polymer particles generated an antibody response for $>5$ months in rats (Raghuvansi et al., 2001).

The failure of the dogs to conceive was not due to failure of mating, as all the four female dogs immunized with recdZP2-DT and three of four animals immunized with DT alone became pregnant subsequent to mating. The ovarian histology of the dogs immunized with rec-dZP3-DT revealed a decrease in the number of primordial follicles, suppression in follicular development and atretic changes in the zona pellucida. In another study, active immunization of marmoset monkeys with purified recombinant human ZP3 also resulted in long-term infertility associated with ovarian dysfunction, characterized by suppression of folliculogenesis and depletion of the pool of primordial follicles (Paterson et al., 1998). These studies indicate that the main mechanism by which anti-rec-dZP3 antibodies cause infertility is by follicular atresia and degenerative changes in the zona pellucida. It is not clear whether these changes are solely a result of anti-rec-dZP3 antibodies or whether there is an involvement of oophoritogenic T cells.

To our knowledge, these studies have evaluated, for the first time, the efficacy of active immunization with rec-dZP2 and rec-dZP3 expressed in E. coli and coupled to DT as a carrier protein to block fertility in female dogs. The observed block in fertility, subsequent to immunization with rec-dZP3-DT, although preliminary, is potentially useful. Attempts are being made in our laboratory to express rec-dZP3 in a glycosylated form using a baculovirus expression system to enhance the immunogenicity of recdZP3.

This work was supported by a grant from the Department of Biotechnology, Government of India. The authors appreciate the help and guidance rendered by M. L. Sharma, P. Sreekumaran, J. S. Dharmadheeran and Narender Singh, Central Military Veterinary Laboratory, Meerut, India, at various stages, for conducting these experiments. Technical assistance by Rajat Ram Gupta and Bhola Ram is gratefully acknowledged.

\section{References}

Bagavant H, Thillai-Koothan P, Sharma MG, Talwar GP and Gupta SK (1994) Antifertility effects of porcine zona pellucida-3 immunization using permissible adjuvants in female bonnet monkeys (Macaca radiata): reversibility, effect on follicular development and hormonal profiles Journal of Reproduction and Fertility 102 17-25

Bleil JD and Wassarman PM (1983) Sperm-egg interactions in the mouse: sequence of events and induction of the acrosome reaction by a zona pellucida glycoprotein Developmental Biology 95 317-324

Bleil JD, Greeve JM and Wassarman PM (1988) Identification of a secondary sperm receptor in the mouse egg zona pellucida: role in maintenance of binding of acrosome-reacted sperm to eggs Developmental Biology 128 376-385

Brown RG, Bowen WD, Eddington JD, Kimmins WC, Mezei M, Parsons JL and Pohajdak B (1997) Evidence for a long-lasting single administration contraceptive vaccine in wild grey seals Journal of Reproductive Immunology 35 43-51

Dunbar BS, Lo C, Powell J and Stevens VC (1989) Use of a synthetic peptide adjuvant for the immunization of baboons with denatured and deglycosylated pig zona pellucida glycoproteins Fertility and Sterility $\mathbf{5 2}$ 311-318

Elin RJ, Wolf SM, McAdam KPW, Audibert F, Bernard C and Oberling F (1981) Properties of reference $E$. coli endotoxin and its phthalylated derivative in humans Journal of Infectious Diseases 144 329-336

Fayrer-Hosken RA, Dookwah HD and Brandon CI (2000) Immunocontrol in dogs Animal Reproduction Science 60-61 365-373

Govind CK and Gupta SK (2000) Failure of female baboons (Papio anubis) to conceive following immunization with recombinant non-human primate zona pellucida glycoprotein-B expressed in Escherichia coli. Vaccine 18 2970-2978

Harris JD, Hibler DW, Fontenot GK, Hsu KT, Yurewicz EC and Sacco AG (1994) Cloning and characterization of zona pellucida genes and cDNAs from a variety of mammalian species: the ZPA, ZPB and ZPC gene families DNA Sequence 4 361-393

Hosaka M, Nagahama M, Kim W, Watanabes T, Hatsuzawa K, Ikemizu J, 
Murakami K and Nakayama K (1991) Arg-X-Lys/Arg-Arg motif as a signal for precursor cleavage catalyzed by furin within the constitutive secretory pathway Journal of Biological Chemistry 26612 127-12 130

Jackson RJ, Maguire DJ, Hinds LA and Ramshaw IA (1998) Infertility in mice induced by a recombinant ectomelia virus expressing mouse zona pellucida glycoprotein-3 Biology of Reproduction 58 152-159

Jethanandani P, Santhanam R and Gupta SK (1998) Molecular cloning and expression in Escherichia coli of cDNA encoding bonnet monkey (Macaca radiata) zona pellucida glycoprotein-ZP2 Molecular Reproduction and Development 50 229-239

Jones GR, Sacco AG, Subramanian MG, Kruger M, Zhang S, Yurewicz EC and Moghissi KM (1992) Histology of female rabbits immunized with deglycosylated zona pellucida macromolecules of pigs Journal of Reproduction and Fertility 95 513-525

Kaul R, Afzalpurkar A and Gupta SK (1997) Expression of bonnet monkey (Macaca radiata) zona pellucida-3 (ZP3) in a prokaryotic system and its immunogenicity Molecular Reproduction and Development $\mathbf{4 7}$ 140-147

Kaul R, Sivapurapu N, Afzalpurkar A, Srikant V, Govind CK and Gupta SK (2001) Immunocontraceptive potential of recombinant bonnet monkey (Macaca radiata) zona pellucida glycoprotein-C expressed in Escherichia coli and its corresponding synthetic peptides Reproductive BioMedicine Online 2 33-39

Laemmeli UK (1970) Cleavage of structural proteins during the assembly of the head of bacteriophage T4 Nature 227 680-685

Lee VH, Schwoebel E, Prasad S, Cheung P, Timmons TM, Cook R and Dunbar BS (1993) Identification and structural characterization of $75 \mathrm{kDa}$ rabbit zona pellucida protein Journal of Biological Chemistry $26812412-12417$

Mahi-Brown CA, Huang TTF, Jr and Yanagimachi $\mathbf{R}$ (1982) Infertility in bitches induced by active immunization with porcine zonae pellucidae Journal of Experimental Zoology 222 89-95

Mahi-Brown CA, Yanagimachi R, Hoffman JC and Huang TTF, Jr (1985) Fertility control in the bitch by active immunization with porcine zonae pellucidae: use of different adjuvants and patterns of estradiol and progesterone levels in estrous cycle Biology of Reproduction 32 761-772

Mahi-Brown CA, Yanagimachi R, Nelson ML, Yanagimachi H and Palumbo $\mathbf{N}$ (1988) Ovarian histopathology of bitches immunized with porcine zonae pellucidae Journal of Reproductive Immunology 13 85-95

Moller CC and Wassarman PM (1989) Characterization of a proteinase that cleaves zona pellucida glycoprotein ZP2 following activation of mouse egg Developmental Biology 132 103-112

Paterson M, Thillai-Koothan P, Morris KD, $\mathrm{O}^{\prime}$ Byrne K, Braude P, Williams A and Aitken RJ (1992) Analysis of the contraceptive potential of antibodies against native and deglycosylated porcine ZP3 in vivo and in vitro. Biology of Reproduction 46 523-534

Paterson M, Wilson MR, Morris KD, van Duin MV and Aitken RJ (1998)
Evaluation of the contraceptive potential of recombinant human ZP3 and human ZP3 peptides in a primate model: their safety and efficacy American Journal of Reproductive Immunology 40 198-209

Raghuvanshi RS, Singh O and Panda AK (2001) Formulation and characterization of immunoreactive tetanus toxoid biodegradable polymer particles Drug Delivery 8 99-106

Sacco AG, Yurewicz EC, Subramanian MG and DeMayo FJ (1981) Zona pellucida composition: species cross reactivity and contraceptive potential of antiserum to a purified pig zona antigen (PPZA) Biology of Reproduction 25 997-1008

Sacco AG, Yurewicz EC and Subramanian MG (1989) Effect of varying dosages and adjuvants on the antibody response in squirrel monkeys (Saimiri sciureus) immunized with the porcine zona pellucida $M_{\mathrm{r}}=$ 55,000 glycoprotein (ZP3) American Journal of Reproductive Immunology 21 1-8

Santhanam R, Panda AK, Kumar SV and Gupta SK (1998) Dog zona pellucida glycoprotein-3 (ZP3): expression in Escherichia coli and immunological characterization Protein Expression and Purification 12 331-339

Skinner SM, Mills T, Kirchik HJ and Dunbar BS (1984) Immunization with zona pellucida proteins results in abnormal ovarian follicular differentiation and inhibition of gonadotrophin induced steroid secretion Endocrinology 115 2418-2432

Sufi SB, Donaldson A and Jeffcoate SL (1999) WHO Matched Assay Reagent Programme: Steroid Radioimmunoassay Method Manual pp 36-46. WHO, Geneva

Talwar GP, Singh O, Pal R et al. (1994) A vaccine that prevents pregnancy in women Proceedings National Academy of Sciences USA 91 8532-8536

Towbin H, Staechelin T and Gordon J (1979) Electrophoretic transfer of proteins from polyacrylamide gels to nitrocellulose sheets Proceedings National Academy of Sciences USA 76 4350-4354

Tsubamoto H, Yamasaki H, Hasegawa A and Koyama K (1999) Expression of a recombinant porcine zona pellucida glycoprotein ZP1 in mammalian cells Protein Expression and Purification 17 8-15

Vandevoort CA, Schwoebel ED and Dunbar BS (1995) Immunization of monkeys with recombinant cDNA expressed zona pellucida proteins Fertility and Sterility 64 838-847

von Heijne G (1986) A new method for predicting signal sequence cleavage sites Nucleic Acid Research 14 4683-4690

Received 20 September 2001.

First decision 20 December 2001

Final manuscript received 12 February 2002.

Accepted 25 February 2002. 